\title{
Acrylamide content in cigarette mainstream smoke and estimation of exposure to acrylamide from tobacco smoke in Poland
}

\author{
Hanna Mojska', Iwona Gielecińska', Andrzej Cendrowski² \\ ${ }^{1}$ Department of Metabolomics, National Food and Nutrition Institute, Warsaw, Poland \\ ${ }^{2}$ Division of Fruit and Vegetable Technology, Department of Food Technology, Faculty of Food Sciences, Warsaw \\ University of Life Sciences (SGGW)
}

Mojska H, Gielecińska I, Cendrowski A. Acrylamide content in cigarette mainstream smoke and estimation of exposure to acrylamide from tobacco smoke in Poland. Ann Agric Environ Med. 2016; 23(3): 456-461. doi: 10.5604/12321966.1219187

\begin{abstract}
Introduction and objective. Acrylamide is a "probably human carcinogen" monomer that can form in heated starchy food as a result of a reaction between asparagine and reducing sugars via Maillard reaction. The main source of acrylamide in human diet are potato products, cereal products and coffee. Tobacco smoke may be another significant source of exposure to acrylamide. The aim of our study was to determine acrylamide content in cigarettes available on the Polish market and to estimate the exposure to acrylamide originating from tobacco smoke in smokers in Poland.

Materials and methods. The material was cigarettes of the top five brands bought in Poland and tobacco from non-smoked cigarettes. Acrylamide content in cigarettes mainstream smoke was determined by LC-MS/MS. Exposure assessment was carried out using analytical data of acrylamide content in cigarettes and the mean quantity of cigarettes smoked daily by smokers in Poland, assuming body weight at $70 \mathrm{~kg}$.

Results. The mean content of acrylamide was $679.3 \mathrm{ng} / \mathrm{cigarette}$ (range: 455.0 - $822.5 \mathrm{ng} / \mathrm{cigarette}$ ). The content of acrylamide was evidenced to correlate positively with total particulate matter (TPM) content in cigarettes. The estimated average exposure to acrylamide from tobacco smoke in adult smokers in Poland is $0.17 \mu \mathrm{g} / \mathrm{kg}$ b.w. $/$ day.

Conclusions. Our results demonstrate that tobacco smoke is a significant source of acrylamide and total exposure to acrylamide in the population of smokers, on average, is higher by more than $50 \%$ in comparison with non-smokers. Our estimation of exposure to acrylamide from tobacco smoke is the first estimation taking into account the actual determined acrylamide content in the cigarettes available on the market.
\end{abstract}

- Key words

Acrylamide, cigarette mainstream smoke, LC-MS/MS, exposure assessment

\section{INTRODUCTION}

Acrylamide (prop-2-enamide; CAS 79-06-1) is a vinyl monomer that has been produced from acrylonitrile on an industrial scale since early 1950s. It is used for the synthesis of polyacrylamide polymers which are extensively applied, for example, as fillers for industrial and drinking water filters, in analytical laboratories as gels for electrophoretic separation of proteins and other ingredients, and in the petroleum, paper, textile and cosmetic industries.

Acrylamide is a neurotoxic compound and may contribute to central and peripheral nervous system damage, both in laboratory animals and in humans exposed to this compound at the workplace $[1,2]$. In animal studies, acrylamide administration in drinking water was associated with an increased incidence of cancer of many organs including testes, heart, uterus, adrenals, thyroid, mammary gland, oral cavity and skin $[3,4]$.

The International Agency for Research on Cancer (IARC) classified acrylamide already in 1994 as a compound 'probably carcinogenic for humans' (Group 2A) [5].

In April 2002, the Swedish National Food Agency in collaboration with scientists from the Stockholm University [6] published for the first time data on the high content of

Address for correspondence: Hanna Mojska, Department of Metabolomics, National Food and Nutrition Institute, 61/63 Powsinska, 02-903 Warsaw, Poland

E-mail: hmojska@izz.waw.pl

Received: 03 September 2013; accepted: 14 May 2014 acrylamide in potato and cereal products processed at high temperatures, mainly by frying and roasting. It is currently known that acrylamide is formed in the course of thermal processing of high-carbohydrate foodstuffs, mainly in the Maillard reaction occurring between free asparagine and reducing sugars - glucose and fructose, under the effect of temperatures above $120^{\circ} \mathrm{C}$ [7]. Acrylamide presence is found in potato products (chips and crisps), in cereal products (bread, breakfast cereals, cookies and biscuits) and in coffee and its substitutes. Dietary exposure to acrylamide has been studied in many countries in recent years $[8,9,10]$. It is estimated that the average exposure to the studied compound ranges from ca. 0.3 - ca. $0.8 \mu \mathrm{g} / \mathrm{kg}$ b.w./day.

Cigarette smoking seems to be the second most important source of exposure to acrylamide after food [11]. However, only a few papers $[12,13,14,15,16]$ on the determination and content of acrylamide in tobacco smoke have been published so far. Additionally, in most of them, the acrylamide content was tested in reference cigarettes Kentucky 1R4F, 2R4F and/ or 3R4F, and not in cigarettes of actual brands available on the market. This is particularly important in view of the fact that, as demonstrated by the studies of Moldoveanu and Gerardi [14] and Xie et al. [16], there are significant differences in the acrylamide content in cigarettes available on the market in different countries. It also significantly varies from its content in the reference cigarettes.

The aim of this study was to determine the acrylamide content in cigarettes of the brands most commonly smoked 
in Poland, to estimate smokers' exposure to acrylamide originating from tobacco smoke.

\section{MATERIALS AND METHOD}

The material for the studies was cigarettes of the top five brands bought in Poland. The share of the studied brands in the cigarette market in Poland ranged from $6.5-14.0 \%$ [17]. A single sample was 10 packs of cigarettes from one production batch, 20 cigarettes per pack, in total 200 cigarettes of each brand. The cigarettes were bought in shops in Warsaw, Poland, in 2012.

Two samples, each of 20 cigarettes intended for smoking, were randomly collected from 200 cigarettes of each brand. All cigarettes intended for smoking were weighed and measured (Tab. 1), and their storage and conditioning took place in a climatic chamber (Binder, Germany) at conditions compliant with the PN-ISO 3402 [18].

Table 1. Characteristics of tested cigarettes

\begin{tabular}{|c|c|c|c|c|c|}
\hline Parameter & $\begin{array}{c}\text { Cigarettes } \\
\text { No. } 1\end{array}$ & $\begin{array}{l}\text { Cigarettes } \\
\text { No. } 2\end{array}$ & $\begin{array}{c}\text { Cigarettes } \\
\text { No. } 3\end{array}$ & $\begin{array}{l}\text { Cigarettes } \\
\text { No. } 4\end{array}$ & $\begin{array}{c}\text { Cigarettes } \\
\text { No. } 5\end{array}$ \\
\hline $\begin{array}{l}\text { Cigarette mass } \\
\text { [g] }\end{array}$ & 0.90 & 1.05 & 1.08 & 0.86 & 1.05 \\
\hline $\begin{array}{l}\text { Cigarette length } \\
{[\mathrm{mm}]}\end{array}$ & 84 & 100 & 100 & 83 & 98 \\
\hline $\begin{array}{l}\text { Sheath length } \\
{[\mathrm{mm}]}\end{array}$ & 33 & 32 & 32 & 32 & 33 \\
\hline $\begin{array}{l}\text { Filter length } \\
{[\mathrm{mm}]}\end{array}$ & 28 & 27 & 27 & 27 & 27 \\
\hline $\begin{array}{l}\text { Butt-end length } \\
{[\mathrm{mm}]}\end{array}$ & 36 & 35 & 35 & 35 & 36 \\
\hline $\begin{array}{l}\text { Nicotine* } \\
\text { [mg/cig] }\end{array}$ & 0.7 & 0.6 & 0.8 & 0.5 & 0.7 \\
\hline $\begin{array}{l}\mathrm{CO}^{*} \\
{[\mathrm{mg} / \mathrm{cig}]}\end{array}$ & 8 & 8 & 10 & 9 & 10 \\
\hline $\begin{array}{l}\text { Tar substances } \\
{[\mathrm{mg} / \mathrm{cig}]}\end{array}$ & 8 & 8 & 10 & 7 & 10 \\
\hline
\end{tabular}

"Information stated on cigarette pack

The smoke stream was generated by single smoking of 20 cigarettes of each brand on a Borgwaldt RM20/CS 20port rotary routine analytical smoking machine. For each cigarette brand, two batches of 20 cigarettes were smoked in parallel. Cigarette storage, conditioning and smoking took place in the Laboratory Unit of the National Control of Harmful Substances in Tobacco Products of the Voivodship Sanitary-Epidemiological Station in Lodz, Poland.

The smoking conditions complied with PN-ISO 3308 [19]. The standard puff volume was $35.0 \pm 0.3 \mathrm{ml}$, puff duration $2.00 \pm 0.02 \mathrm{~s}$, and puff frequency - one puff per $60.0 \pm 0.5 \mathrm{~s}$. The temperature and relative humidity of the environment were $22 \pm 2{ }^{\circ} \mathrm{C}$ and $60 \pm 5 \%$, respectively.

Total particulate matter (TPM) is the portion of the mainstream cigarette smoke which is caught in the smoke trap. In the presented study, acrylamide was assayed only in the particulate phase of smoke stream, because the content of the tested compound in the vapour phase is very small [13]. Total particulate matter samples were collected on glass fibre filters (100\% borosilicate glass, diameter $92 \mathrm{~mm}$, weight $220 \mathrm{~g} / \mathrm{m}^{2}$, thickness $1 \mathrm{~mm}$, retaining power $0.3 \mu \mathrm{m}, \mathrm{pH}$-value
7.2-7.8; Borgwaldt Technik GmbH, Hamburg, Germany). In the thus collected TPM, acrylamide was assayed by LCMS/MS.

Additionally, for the purpose of acrylamide assay in nonsmoked cigarettes, five cigarettes were selected randomly from each of two selected cigarette brands (cigarettes No. 1 and cigarettes No. 3). Each of five cigarettes of one brand was manually separated into tobacco, paper and the filter, and then tobacco from five cigarettes was combined, mixed and weighed. Papers and filters were weighed separately. Acrylamide content was determined in the thus prepared samples of tobacco of two brands of non-smoked cigarettes, immediately after their preparation. In parallel, the content of the tested compound was measured in two brand new glass filters for collecting total particulate matter.

Reagents, reference solutions and columns. Acrylamide (AA; 99.5+\%) was supplied by Fluka Chemie GmbH (Switzerland). The internal standard - deuterated acrylamide $\left(\operatorname{AAd}_{3} ; 2,3,3\right.$ $\mathrm{d}_{3}$ acrylamide; $98 \%$ ) - was supplied by Cambridge Isotope Laboratories Inc. (Andover, MA, USA). Methanol HPLC (99.9\%) was supplied by Rathburn Chemicals (Walkerburn, Scotland, UK), and methanol LC-MS (99.8+) and formic acid LC-MS (99+\%) supplied by Mallinckrodt Baker BV (Deventer, Netherlands). Bakerbond Carbon Columns (1000 mg; $6 \mathrm{ml}$ ) made by Mallinckrodt Baker BV (Deventer, Netherlands) were used for solid phase extraction (SPE).

Stock solutions of acrylamide and deuterated acrylamide were obtained by dissolving $2.5 \mathrm{mg}$ of each substance in $25 \mathrm{ml}$ of deionised water, and then diluting to $10,000 \mathrm{ng} / \mathrm{ml}$ (solution $\mathrm{AA}$ ) and $1,000 \mathrm{ng} / \mathrm{ml}\left(\mathrm{AAd}_{3}\right)$. The internal standard $\left(\mathrm{AAd}_{3}\right)$ solution at a concentration of $250 \mathrm{ng} / \mathrm{g}$ was added to all samples.

Sample preparation. The filter with the collected total particulate matter was placed in a centrifuge tube and then the internal standard $\left(\mathrm{AAd}_{3}, \mathrm{c}=10,000 \mathrm{ng} / \mathrm{ml}\right)$ was added in a quantity of 21 to $27 \mu \mathrm{g}$, depending on particulate matter mass, along with $33 \mathrm{ml}$ of deionised water. The samples were shaken mechanically (PROMAX 1020, Heidolph, Germany; $10 \mathrm{~min}, 257 \mathrm{rpm}$ ) at room temperature. Then the samples were incubated in an ultrasonic water bath (BAS, Poland; $60^{\circ} \mathrm{C}$; $30 \mathrm{~min}$ ). After cooling down to room temperature, supernatant was collected into a conical flask and the residue was centrifuged (MPW 350R, Poland; $10 \mathrm{~min}$; 10,000 rpm), the filter carefully removed from the tube and the remaining centrifuged solution was combined with the previously obtained supernatant. Two samples of un-heated tobacco were prepared in a similar way as TPM samples. The prepared samples were purified by solid phase extraction (SPE).

Supernatant $(10 \mathrm{ml})$ was applied to carbon columns (SPE) previously conditioned with methanol for HPLC $(8 \mathrm{ml})$ and then with water $(8 \mathrm{ml})$. After sample passage, the columns were flushed with water $(1 \mathrm{ml})$, dried under a vacuum for $15 \mathrm{~min}$, after which the tested compounds were eluted with methanol for HPLC $(5 \times 2 \mathrm{ml})$. The collected eluents were evaporated to dryness on a heating block at not more than $50^{\circ} \mathrm{C}$, under a gentle nitrogen stream. The dry residue of the samples was dissolved in $1 \mathrm{ml}$ of the mixture of water and methanol $(9: 1, \mathrm{v} / \mathrm{v})$, transferred to an amber vial and analysed by LC-MS/MS, as described before [20]. Before LC-MS/MS analysis, TPM samples were additionally diluted ten times with the above mixture of water and methanol $(9: 1, \mathrm{v} / \mathrm{v})$. 
Analysis of acrylamide by LC-MS/MS. A liquid chromatograph Ultimate 3000 (Dionex) coupled to a triple quadrupole mass spectrometer 3200 QTrap (ABSciex, USA) was used for the analyses. Chromatographic separation was conducted on the Hypercarb column $(5 \mu \mathrm{m}, 150 \times 2.1 \mathrm{~mm})$ with a $5 \mu \mathrm{m}$, $10 \times 2.1 \mathrm{~mm}$ (Thermo Scientific) guard column.

Chromatographic separation conditions were as follows: column flow rate $350 \mu \mathrm{l} / \mathrm{min}$, column temperature $20^{\circ} \mathrm{C}$, mobile phase: water and methanol for LC-MS $(9: 1 ; \mathrm{v} / \mathrm{v})$ with $0.1 \%$ formic acid addition, analysis time $5 \mathrm{~min}$, as previously described [20]. The assay of acrylamide in total particulate matter and in tobacco was conducted by MRM with positive polarisation. Transitions $m / z 72.1 \rightarrow 55.2(\mathrm{AA})$ and $m / z 75.1 \rightarrow 58.1\left(\mathrm{AAd}_{3}\right)$ were monitored for use in quantitative assay of acrylamide in total particulate matter and tobacco, while transitions $\mathrm{m} / z 72.1$ $\rightarrow 44.1(\mathrm{AA})$ and $m / z 75.1 \rightarrow 47.1\left(\mathrm{AAd}_{3}\right)$ were monitored for the purposes of verification of the results obtained.

Quality control. The LC-MS/MS method of acrylamide assay in total particulate matter was validated. The following parameters were determined: selectivity, limit of quantification (LOQ), precision, repeatability and accuracy by recovery testing.

Estimation of exposure to acrylamide originating from tobacco smoke. The exposure of adult smokers in Poland to acrylamide originating from tobacco smoke was estimated with the use of the measured analytical data of acrylamide content in cigarettes, and of the mean quantity of cigarettes smoked daily by smokers in Poland [21]. Only those persons who smoked cigarettes daily and not occasionally were taken into account in the acrylamide exposure estimation. The exposure of adult smokers was estimated at three levels: minimum, average and maximum, taking into account the measured minimum and maximum content of acrylamide in cigarettes and the calculated mean content. Exposure to tobacco smoke acrylamide in $\mu \mathrm{g} /$ $\mathrm{kg}$ b.w./day was calculated with the assumption that the mean body weight of an adult is $70 \mathrm{~kg}$.

Statistical analysis. Acrylamide content in tobacco smoke is presented as a mean \pm SD in ng/g of tobacco and ng/cigarette. Exposure of the population of adult smokers in Poland is expressed in $\mu \mathrm{g} / \mathrm{kg}$ b.w./day. The correlation between acrylamide content and total particulate matter (TPM) in cigarettes was determined with the use of the Pearson's linear correlation coefficient, and its significance verified by the $\mathrm{t}$-Student test for correlation coefficient.

\section{RESULTS}

Validation of the LC-MS/MS method. For the purpose of the presented study, the authors' own method of acrylamide determination in food [20] was modified on the basis of the available literature $[14,16]$ The LC-MS/MS method of acrylamide determination in total particulate matter and tobacco was validated. On the basis of the results obtained, this method was found to enable the correct separation of the tested compound from other matrix ingredients, and obtaining daughter ions characteristic for acrylamide $(\mathrm{m} / z=55.2$ and $\mathrm{m} / z=44.1)$ and deuterated acrylamide $(\mathrm{m} / z=58.1$ and $\mathrm{m} / z=47.1)$, and thus to be specific for the tested compounds (Fig. 1).

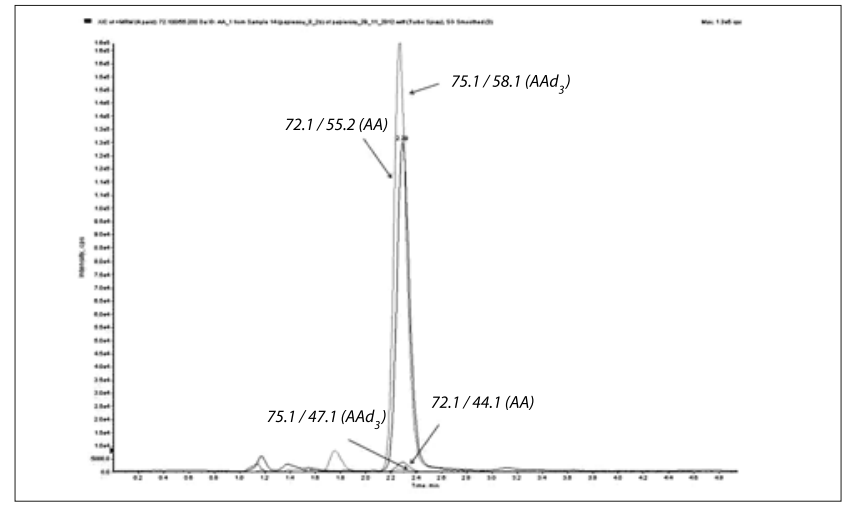

Figure 1. Typical MRM chromatogram of acrylamide and $d_{3}$-acrylamide ions in TPM

The limit of quantification was determined on the basis of the signal-to-noise ratio $(\mathrm{S} / \mathrm{N}=10)$. The $\mathrm{S} / \mathrm{N}$ ratio was calculated with the use of the Savitzky-Goolay Smith and Signal-to noise (ABSciex, USA) scripts. The limit of quantification is $2.5 \mathrm{ng} / \mathrm{ml}$. A seven-point calibration curve was plotted over the range of $50-600 \mathrm{ng} / \mathrm{ml}(\mathrm{r}=1.0000$; $n=3$ ), taking into account the expected content of acrylamide in total particulate matter. For non-smoked cigarettes and brand new filters, an eight-point calibration curve was plotted over the range of $2.5-200 \mathrm{ng} / \mathrm{ml}(\mathrm{r}=0.9999 ; \mathrm{n}=3)$. Within the whole range of both curves, the obtained validation parameters were very good (curve over the range of 50$600 \mathrm{ng} / \mathrm{ml}$ - within-day precision: $\mathrm{RSD}<0.8 \%$, bias $\pm 1.1 \%$; between-day precision: $\mathrm{RSD}<2.9$; bias $\pm 0.8 \%$ and curve over the range of $2.5-200 \mathrm{ng} / \mathrm{ml}$ - within-day precision: $\mathrm{RSD}<2.8$, bias $\pm 2.9 \%$; between-day precision: $\mathrm{RSD}<4.0 \%$; bias $\pm 5.5 \%$ ). Precision of the method was determined by the analysis of parallel samples of total particulate matter $(\mathrm{RSD}=1.3 \%)$ and non-smoked cigarettes ( $\mathrm{RSD}=2.7 \%)$. The accuracy of the method was verified on the basis of analysis of recovery of the tested compound. The mean recovery for acrylamide in total particulate matter was $96.3 \%$, and in tobacco - $120.5 \%$. At each assay series, one blanc sample and two standard solutions were injected in order to verify stability of the calibration curve. The obtained validation results indicate that the LC-MS/MS method of acrylamide determination in total particulate matter is specific for the tested compound and is characterised both by good precision and accuracy.

Acrylamide content in tobacco smoke and estimation of exposure to acrylamide from cigarettes. Five samples of total particulate matter and two samples of tobacco originating from non-smoked cigarettes were tested for acrylamide content by the LC-MS/MS method described in this study. The results are presented in Tables 2 and 3.

Table 2. Acrylamide content in various cigarette brands sampled in the Polish market

\begin{tabular}{|c|c|c|c|c|c|}
\hline \multirow[b]{2}{*}{ Cigarette brand } & \multirow{2}{*}{$\begin{array}{c}\text { Cigarette } \\
\text { mass (20 } \\
\text { cigarettes) } \\
{[\mathrm{g}]}\end{array}$} & \multirow{2}{*}{$\begin{array}{c}\mathrm{TPM}^{*} \\
{[\mathrm{mg} / 20} \\
\text { cigarettes] }\end{array}$} & \multirow{2}{*}{$\begin{array}{c}\mathrm{TPM}^{*} \\
{[\mathrm{mg} /} \\
\text { cigarette] }\end{array}$} & \multicolumn{2}{|c|}{ Acrylamide content } \\
\hline & & & & $\begin{array}{c}{[\mathrm{ng} / \mathrm{mg}} \\
\text { TPM] }\end{array}$ & $\begin{array}{c}{[\mathrm{ng} /} \\
\text { cigarette] }\end{array}$ \\
\hline Cigarettes No. 1 & 18.0 & 194.8 & 9.76 & 79.2 & 771.7 \\
\hline Cigarettes No. 2 & 21.0 & 177.4 & 8.87 & 62.0 & 550.0 \\
\hline Cigarettes No. 3 & 21.6 & 236.0 & 11.80 & 69.8 & 822.5 \\
\hline Cigarettes No. 4 & 17.1 & 142.9 & 7.14 & 63.7 & 455.0 \\
\hline Cigarettes No. 5 & 21.0 & 203.6 & 10.18 & 78.3 & 797.5 \\
\hline$x \pm S D$ & - & - & - & $70.6 \pm 8.0$ & $679.3 \pm 165.9$ \\
\hline
\end{tabular}

total particulate matter 


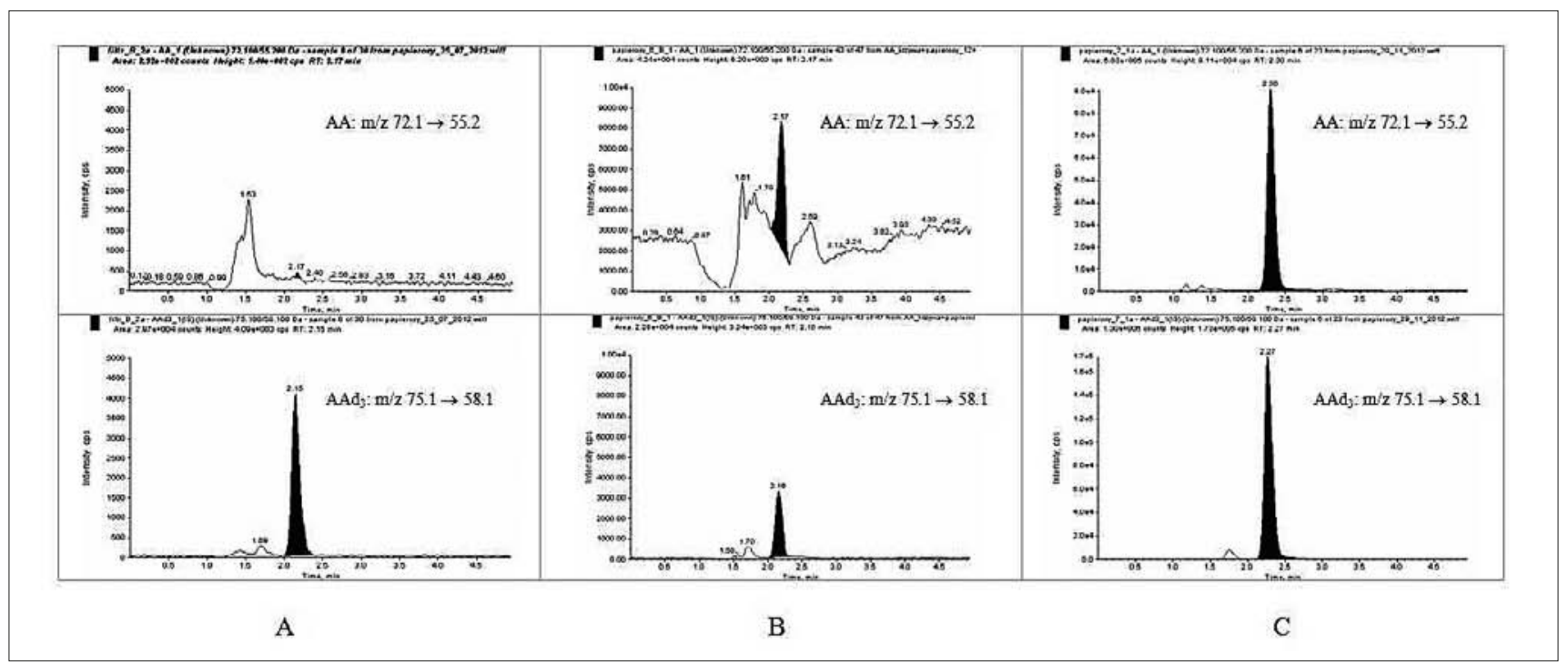

Figure 2. MRM chromatograms showing the ions mass of $A A$ and $A A d_{3}$ determined in the samples of a new filter (A), an unheated tobacco (B) and a total particulate matter (TPM) originated from 20 smoked cigarettes (C) spiked at $250 \mathrm{ng} / \mathrm{g}$ of internal standard $\left(\mathrm{AAd}_{3}\right)$

The level of total particulate matter (TPM) originating from the two smoking processes ranged from $7.14-$ $11.80 \mathrm{mg} /$ cigarette (Tab. 2). The differences between TPM quantities originating from parallel smoking of cigarettes of one brand did not exceed 5\% (data not shown).

The determined acrylamide content in total particulate matter ranged from $62.0 \mathrm{ng} / \mathrm{g}$ TPM (cigarette No. 2) - $79.2 \mathrm{ng} / \mathrm{g}$ TPM (cigarette No. 1) (Tab. 2). Taking into account the mass of cigarettes of each brand, the acrylamide content per one cigarette was calculated. The mean content of acrylamide per one cigarette was $679.3 \mathrm{ng}(455.0 \div 822.5 \mathrm{ng})$.

Acrylamide content in unheated cigarettes was significantly lower than in smoked cigarettes and represented $8.2 \%$ and $6.1 \%$ of the acrylamide level found in the same brands of smoked cigarettes, respectively (Tab. 3). No acrylamide was found in any of the brand new filters used for collecting total particulate matter (Fig. 2).

Table 3. Acrylamide content in various unheated tobacco from two cigarette brands

\begin{tabular}{|c|c|c|c|}
\hline \multirow{2}{*}{ Cigarette brand } & \multirow{2}{*}{$\begin{array}{c}\text { Tobacco content } \\
\text { [g/cigarette] }\end{array}$} & \multicolumn{2}{|c|}{ Acrylamide content } \\
\hline & & [ng/g tobacco] & [ng/cigarette] \\
\hline Cigarettes No. 1 & 0.591 & 106.0 & 63.3 \\
\hline Cigarettes No. 3 & 0.643 & 77.2 & 49.7 \\
\hline
\end{tabular}

A significant $(\mathrm{p}<0.0005)$ positive correlation was found between the measured acrylamide content and the mass of total particulate matter in a cigarette $(r=0.9014)$.

Estimation of exposure to acrylamide originating from tobacco smoke. Table 4 presents the estimated exposure to acrylamide from tobacco smoke in populations of smoking adults in Poland at three levels: minimum, average and maximum.

It was assumed that the calculated mean content of the tested compound in cigarettes, average acrylamide intake with tobacco smoke, was $11.66 \mu \mathrm{g} /$ person/day. In the female group, this was by approximately $15 \%$ lower than in the male group. When the intake was estimated at the minimum level, which takes into account the lowest measured acrylamide
Table 4. Mean acrylamide intake from cigarettes among adult smokers in the Polish population

\begin{tabular}{|c|c|c|c|c|c|c|c|}
\hline \multirow[t]{2}{*}{ Group } & \multirow{2}{*}{$\begin{array}{c}\text { Mean No. of } \\
\text { cigarettes smoked } \\
\text { daily by a smoker } \\
{[p c s]^{*}}\end{array}$} & \multicolumn{3}{|c|}{$\begin{array}{c}\text { Acrylamide intake from } \\
\text { tobacco smoke } \\
{[\mu g / \text { person/day] }}\end{array}$} & \multicolumn{3}{|c|}{$\begin{array}{c}\text { Exposure to acrylamide } \\
\text { from tobacco smoke } \\
{[\mu g / \mathrm{kg} b . w . / \text { day }]}\end{array}$} \\
\hline & & $\min$. & average & $\max$. & $\min$. & average & $\max$. \\
\hline Total & 17.17 & 7.81 & 11.66 & 14.12 & 0.11 & 0.17 & 0.20 \\
\hline Females & 15.51 & 7.06 & 10.54 & 12.76 & 0.10 & 0.15 & 0.18 \\
\hline Males & 18.31 & 8.33 & 12.44 & 15.06 & 0.12 & 0.18 & 0.22 \\
\hline
\end{tabular}

"Source: GATS Poland 2009-2010

content in cigarettes, the acrylamide intake was lower almost by half, compared to average intake. For the worst-case scenario, where the highest measured acrylamide content in cigarettes was taken for the calculations, this intake attained $15.06 \mu \mathrm{g} /$ person/day in the group of adult men.

When the acrylamide intake was calculated per $\mathrm{kg}$ body weight, the mean estimated exposure to acrylamide originating from cigarettes at the minimum level was $0.11 \mu \mathrm{g} / \mathrm{kg}$ b.w./day, ranging from $0.10 \mu \mathrm{g} / \mathrm{kg} /$ day in the female group to $0.12 \mu \mathrm{g} / \mathrm{kg}$ b.w./day in the male group. The average exposure is more than half higher, and at the maximum level is almost twice as high (Tab. 4).

\section{DISCUSSION}

Assessment of the risk related to acrylamide exposure must take into account all the main sources of its origin - both food and tobacco smoke. Only a few papers $[12,13,14,15,16]$ on the determination and content of acrylamide in tobacco smoke have been published to-date. Additionally, in most of them, acrylamide content was tested in reference cigarettes Kentucky 1R4F, 2R4F and/or 3R4F, and only in two studies $[14,16]$ the authors measured acrylamide in cigarettes of actual brands available on the market. The presented study assayed acrylamide in the five most popular cigarette brands in Poland, by the LC-MS/MS method which was optimised and validated. The obtained results of selectivity, limit of quantification, precision, repeatability and accuracy, evidence 
that the method can be used for acrylamide determination in tobacco smoke. Since acrylamide is present mainly in the solid phase of tobacco smoke [13], in the current study total particulate matter (TPM) was collected on glass filters after cigarette smoking in a routine analytical smoking machine. The content of total particulate matter in the tested five cigarette brands was similar and ranged from $7.14 \mathrm{mg} /$ cigarette - $11.80 \mathrm{mg} /$ cigarette. Significantly higher results were obtained by Moldoveanu and Gerardi [14] who tested seven cigarette brands in the USA (range: $6.30 \mathrm{mg} /$ cigarette $\div 22.69 \mathrm{mg} /$ cigarette). It should be emphasised that in American studies the cigarettes were not dried and conditioned before smoking, and the so-called wet total particulate matter (WTPM) was collected on filters after smoking, which contained $10 \%$ water and appropriately increased its weight. Nevertheless, when comparing the TPM content in Polish cigarettes and WTPM in US cigarettes, it should be stated that in the latter the content of total particulate matter, on average, was by approximately $40 \%$ higher than in the cigarettes in Poland.

The acrylamide content measured in the presented study on five different cigarette brands ranged from $455.0 \mathrm{ng} /$ cigarette $-822.5 \mathrm{ng} / \mathrm{cigarette}$, but in three of the five tested brands it was approximately and above $800 \mathrm{ng} /$ cigarette. The results obtained in this study were lower than those in the studies of Moldoveanu and Gerardi [14], who found indeed the lowest content of the tested compound at a level close to the presented results (497.1 ng/cigarette), but for most of the tested cigarettes in the USA, the acrylamide content ranged from more than 1,000 ng/cigarette to over 2,700 ng/cigarette. The difference found was attributed mainly to the abovedescribed higher content of WTPM in cigarettes in the USA. Similar to the American studies [14], in the presented study, a significant positive correlation $(\mathrm{r}=0.9014 ; \mathrm{p}<0.0005)$ was found between acrylamide content and TPM content in the cigarettes. Therefore, the higher content of both WTPM and TPM is related to a higher content of acrylamide in the cigarettes. Simultaneously, a significant positive correlation $(\mathrm{r}=0.9899 ; \mathrm{p}<0.001)$ was found between TPM content and nicotine content in the cigarettes (data not shown). The results obtained are evidence that cigarettes with a higher 'strength' have a higher content of TPM and acrylamide. The highest results of acrylamide content in cigarettes have been found so far by Xie et al. [14] in three main cigarette brands in China. The content of the tested compound measured by the above authors ranged from 4,753 ng/cigarette to 7,991 ng/cigarette. The authors did not state the TPM content in the tested cigarettes.

The presented study also determined the acrylamide in tobacco from non-smoked cigarettes of two out of five tested brands. Acrylamide content in the tobacco was less than $10 \%$ of the content measured in smoked cigarettes of the same brands. Moldoveanu and Gerardi [14] also found acrylamide content in tobacco that had not been subjected to the smoking process. The acrylamide content measured by them was slightly higher than the values obtained in the current study. In contrast to the presented results and US studies [14], Xie et al. [16] stated that in their study 'no signal has been found from unheated tobacco', which was interpreted by the authors as confirmation that acrylamide is created exclusively in the process of cigarette smoking. The results obtained in the current study in unheated tobacco seem to confirm earlier reports $[13,22]$ of the presence of acrylamide precursors in tobacco leaves, and indicate the possibility of the formation of the tested compound, for example, in the raw material drying process. Diekmann et al. [13] indicate three possible mechanisms of acrylamide formation in tobacco: 1) reversible reaction of ammonia with acrylic acid;2) reaction of asparagine with reducing sugars; 3 ) acrylamide formation from acrolein. All three reactions are also listed as possible mechanisms of acrylamide formation in food [7], and the presence of all the above precursors was found in tobacco [22] and in tobacco smoke [14]. At the same time, the low content of acrylamide in unheated tobacco measured in the presented study, in comparison with its content in total particulate matter remaining after the same cigarette brands have been smoked, unequivocally indicates that acrylamide is formed mainly in the smoking process.

The determined content of acrylamide in tobacco smoke from actual cigarettes available on the market was used for estimating the exposure to acrylamide among the smoker population in Poland. The overall percentage of smokers in Poland is $23.8 \%$ [23] and the mean number of cigarettes smoked daily is slightly above 17 [21]. Men, on average, smoke a little more than 18 cigarettes and women smoke 15.5 cigarettes daily. The authors are well aware that the conditions of smoking cigarettes in the smoking machine according to the ISO regime differ substantially from smoking by smokers. The differences relate to the puff volume, puff duration and puff frequency $[24,25,26,27]$. These differences may affect the total amount of the substances getting into the human body with tobacco smoke [28]. However, despite the fact that smoking in the smoking machine according to the ISO regime does not reflect the actual human topography of smoking, it is currently the only recommended method used in the study of the content of toxic compounds in cigarette smoke. Taking into account the measured minimum and maximum content of acrylamide in cigarettes, and the calculated mean content of acrylamide ( $679 \mathrm{ng} /$ cigarette), the current study estimated the exposure to the tested compound among the smokers in Poland. The average exposure in the population of adult smokers is $0.17 \mu \mathrm{g} / \mathrm{kg}$ b.w./day, ranging from $0.10 \mu \mathrm{g} / \mathrm{kg}$ b.w. $/$ day (women) $-0.22 \mu \mathrm{g} / \mathrm{kg}$ b.w./day (men).

The presented estimation of exposure to acrylamide from tobacco smoke is the first to take into account the actual determined acrylamide content in cigarettes available on the market. The estimations published to-date, based on the acrylamide content in tobacco smoke [29], took into account the content of acrylamide measured only in the reference cigarettes Kentucky 1R4F, 2R4F or 3R4F. However, as demonstrated by Moldoveanu and Gerardi [14], the values for these cigarettes are overestimated, which in the authors' opinion may be associated with the potential coelution of acrylamide with another compound with $m / z=71$ fragmentation potential. In the opinion of the above-quoted authors, the actual content of acrylamide in tobacco smoke originating from the Kentucky $2 \mathrm{R} 4 \mathrm{~F}$ and $3 \mathrm{R} 4 \mathrm{~F}$ cigarettes is significantly lower. In view of the disclosed differences in acrylamide content in cigarettes in the current study, and in studies of actual cigarettes in the USA [14] and in China [16], the acrylamide content in market cigarette brands available in the given country, rather than in reference cigarettes, should be taken into account when estimating the actual exposure to this compound from tobacco smoke in population groups.

As demonstrated in previous studies by the authors of this study [30], the average exposure to acrylamide from 
food in the adult population in Poland (19-96 years of age) is $0.33 \mu \mathrm{g} / \mathrm{kg}$ b.w./day. The currently obtained data demonstrate that in the population of smokers, total exposure to acrylamide, on average, is higher by more than $50 \%$ in comparison with non-smokers. This exposure is higher by approximately $10 \%$ in the group of men, in comparison with women.

\section{CONCLUSIONS}

It should be stated that the optimised LC-MS/MS method of determination of acrylamide in cigarette smoke and unheated tobacco with purification on carbon columns is characterised by good selectivity, precision and accuracy. It was found that the acrylamide level in the most popular market cigarette brands available in Poland ranged from $455 \mathrm{ng} /$ cigarette $822.5 \mathrm{ng} /$ cigarette. The content of acrylamide in cigarettes was evidenced to correlate positively with the total particulate matter content and with the cigarette 'strength' expressed as nicotine content. Acrylamide content in non-smoked tobacco may indicate the presence of precursors of the tested compound in the raw material. Tobacco smoke is a significant source of acrylamide, a compound probably carcinogenic to humans. The estimated total exposure to acrylamide in the smoker group is higher almost by half than in non-smokers.

\section{Acknowledgments}

This study was funded by Grant No. N N404 067740 from the Polish National Science Centre in Krakow, Poland. The authors extend their thanks to Mrs. Teresa Trafalska from the Laboratory Unit of the National Control of Harmful Substances in Tobacco Products of the Voivodship SanitaryEpidemiological Station in Lodz, Poland, for her technical assistance in the process of smoking cigarettes.

\section{REFERENCES}

1. Hagmar L, Törnqvist M, Nordander C, Rosén I, Bruze M, Kautiainen A, et al. Health effects of occupational exposure to acrylamide using hemoglobin adducts as biomarkers of internal dose. Scand J Work Environ Health. 2001; 27 (4): 219-226.

2. He FS, Hang SL, Wang HL, Li G, Hang ZM, Li FL, et al. Neurological and electroneuromyographic assessment of the adverse effects of acrylamide on occupationally expose workers. Scand J Work Environ Heath. 1989; 15: $125-129$

3. Friedman MA, Duak LH, Stedham MA. A lifetime oncogenicity study in rats with acrylamide. Fundam Appl Toxicol. 1995; 27: 95-105.

4. Johnson K, Gorzinski S, Bodnar K, Campbell R, Wolf C, Friedman $\mathrm{M}$, et al. Chronic toxicity and oncogenicity study on acrylamide incorporated in the drinking water of Fisher 344 rats. Toxicol Appl Pharmacol. 1986; 85: 154-168.

5. International Agency for Research on Cancer (IARC): Acrylamide, IARC monographs on the evaluation of carcinogenic risks to humans. Some industrials chemicals, vol. 60. International Agency for Research on Cancer: Lyon, France, 1994, 389-433 http://www.iarc.fr/ENG/ Databases/index.php

6. SNFA. Swedish National Food Administration. Information about acrylamide in food. 2002 http://www.slv.se/engdefault.asp

7. Taeymans D, Wood J, Ashby P, Blank I, Studer A, Stadler RH, et al. A review of acrylamide: An industry perspective on research, analysis, formation, and control. Crit Rev Food Sci Nutr. 2004; 44: 323-347.
8. Konings EJM, Baars AJ, van Klaveren JD, Spanjer MC, Rensen PM, Hiemstra M, et al. Acrylamide exposure from foods of the Dutch population and an assessment of the consequent risk. Food Chem Toxicol. 2003; 41: 1569-1579.

9. Normandin L, Bouchard M, Ayotte P, Blanchet C, Becalski A, Bonvalot $\mathrm{Y}$, et al. Dietary exposure to acrylamide in adolescents from Canadian urban center. Food Chem Toxicol. 2013; 57: 75-83.

10. Sirot V, Hommet F, Tard A, Leblanc JC. Dietary acrylamide exposure of the French population: Results of the second French Total Diet Study. Food Chem Toxicol. 2012; 50: 889-894.

11. Hagmar L, Wirfält E, Paulsson B, Törnqvist M. Differences in hemoglobin adduct levels of acrylamide in the general population with respect to dietary intake, smoking habits and gender. Mutat Res. 2005; 580: 157-165.

12. deBethizy JD, Borgerding MF, Doolittle DJ, Robinson JH, McManus $\mathrm{KT}$, Rahn BS, et al. Chemical and biological studies of a cigarette that heats rather than burns tobacco. J Clin Pharmacol. 1990; 30: 755-763.

13. Diekmann J, Wittig A, Stabbert R. Gas chromatographic-mass spectrometric analysis of acrylamide and acetamide in cigarette mainstream smoke after on-column injection. J Chromatogr Sci. 2008; 46, August: 659-663.

14. Moldoveanu SC, Gerardi AR. Acrylamide analysis in tobacco, alternative tobacco products, and cigarette smoke. J Chromatogr Sci. 2011; 49: 234-242.

15. White EL, Uhrig MS, Johnson TJ, Gordon BM, Hicks RD, Borgerding MF, et al. Quantitative determination of selected compounds in a Kentucky 1R4F reference cigarette smoke by multidimensional gas chromatography and selected ion monitoring-mass spectrometry. J Chromatogr Sci. 1990; 28, August: 393-399.

16. Xie S, Wang K, Zhu R, Zhu X, Wie W. Solid phase extraction-ultra performance liquid chromatography for the determination of acrylamide in mainstream cigarette smoke. Mendeleev Commun. 2009; 19: 344-345.

17. Millward Brown, Target Group Index (TGI) project, January 2004 March 2011 (unpublished data).

18. PN-ISO 3402:2002 Tobacco and tobacco products. Atmosphere for conditioning and testing.

19. PN-ISO 3308:2002 Cigarettes. Routine analytical cigarette smoking machine. Definitions and standard conditions.

20. Mojska H, Gielecińska I, Stoś K. Determination of acrylamide level in commercial baby foods and an assessment of infant dietary exposure. Food Chem Toxicol. 2012; 50: 2722-2728.

21. Global Adult Tobacco Survey - GATS. http://www.wsse.webserwer.pl/ UserFiles/wsse/File/OSW_N_STR/ tob3cit_v/GATS.pdf

22. Schmeltz I, Hoffmann D. Nitrogen-containing compounds in tobacco and tobacco smoke. Chem Rev. 1977; 77: 295-311.

23. Central Statistical Office. Statistical Yearbook of the Republic of Poland. Warsaw, LXX1, 2011.

24. Strasser AA, Pickworth WB, Paterson F, Lerman C. Smoking topography predict abstinence following treatment with nicotine replacement therapy. Cancer Epidemiol Biomarkers Prev. 2004; 13: 1800:1804.

25. Hammond D, Fong GT, Cummings KM, Hyland A. Smoking topography, brand switching, and nicotine delivery: results from an in vivo study. Cancer Epidemiol Biomarkers Prev. 2005; 14: 1370-1375.

26. Kassel JD, Greenstein JE, Evatt DP, Wardle MC, Yates MC, Veilleux JC, et al. Smoking topography in response to denicatinized and highyield nicotine cigarettes in adolescent smokers. J Adolesc Health. 2007; 40: 54-60.

27. Czogała J, Goniewicz MŁ, Czubek A, Koszowski B, Sobczak A. Jak naprawdę pali palacz - wyniki wstępne badań topografii palenia populacji palaczy w Polsce. Przegl Lek. 2008; 65: 657-662

28. Hammond D, Collishaw NE, Callard C. Secret science: tobacco industry research on smoking behaviour and cigarette toxicity. Lancet 2006; 367: 781:787

29. German Federal Environment Agency: Acrylamide and human biomonitoring. 2008. http://www.umweltdaten.de/gesundheit-e/ monitor/acrylamide_and_hbm.pdf

30. Mojska H, Gielecińska I, Szponar L, Ołtarzewski M. Estimation of the dietary acrylamide exposure of the Polish population. Food Chem Toxicol. 2010; 48: 2090-2096. 